\title{
Effects of Whole-body Magnetic Field on Changes of Glucose and Cortisol Hormone in Guinea Pigs
}

\author{
${ }^{1}$ Zare S., ${ }^{1}$ Hayatgeibi H., ${ }^{1}$ Alivandi S. and ${ }^{2}$ Ebadi A.G. \\ ${ }^{1}$ Department of Biology, Faculty of Sciences, Urmia University, Urmia, Iran \\ ${ }^{2}$ Department of Biology, Islamic Azad University of Sari, Sari Branch 48164-194, Iran
}

\begin{abstract}
The main goal of this study was to evaluate the possible effect of whole-body Magnetic Field (MF) exposure on the variations of glucose and corlisol hormone levels on 36 adult male Guinea pigs in four separate experiments, male Guinea pigs, were exposed to sinusoidal $5 \mathrm{~Hz}, 0.013 \mu \mathrm{T}$ and $50 \mathrm{~Hz}-0.207 \mu \mathrm{T}$ MF. Duration of exposure was 2 and $4 \mathrm{~h}$ /day over a period of 5 days. At the end of the exposure, blood samples were isolated and level of Serum glucose measured by Auto analyzer. cortisol content of blood sera was assayed by radioimmunoassay (RIA).We found significant decreases in the levels of glucose and cortisol hormone in $50 \mathrm{~Hz}-0.207 \mu \mathrm{T}$ MF after $2 \mathrm{~h}$ exposure $(\mathrm{p}<0.05)$. This condition was seen only for Glucose hormone after $4 \mathrm{~h}$ exposure $(\mathrm{p}<0.05)$. In all test samples, exposure after 2 or $4 \mathrm{~h}$ in $50 \mathrm{~Hz}-0.207 \mu \mathrm{T}$, showed greater decrease compared to $5 \mathrm{~Hz}, 0.013 \mu \mathrm{T}$ MF exposure. Our results indicated that a presumably direct effect of whole-body MF exposure on levels of glucose and cortisol hormones.
\end{abstract}

Key words: Magnetic fields, glucose, cortisol, hormone, guinea pigs

\section{INTRODUCTION}

Numerous biochemical studies have been carried out to evaluate the effects of electric and magnetic fields on the metabolism of cell ${ }^{[1-3]}$. The studies showed significant disturbances in the metabolism of carbohydrate, lipid and protein reflected by altered blood glucose levels and by accelerated glycolysis and glycogenolysis with a metabolic block of conversion of pyruvic acid to acetylocoenzyme A. The levels of total protein and its fractions were also changed. The Krebs cycle was disturbed probably due to a metabolic block of conversion of alpha-ketoglutaric acid to succinylcoenzyme A. It is likely that the disturbances lead to adaptative changes, which in turn result in altered lactate dehydrogenase activity and accelerated tiansamination processes ${ }^{[4-6]}$. Electromagnetic fields penetrate the animal body and act on all organs, altering the cell membrane potential and the distribution of ions and dipoles. These alterations may influence biochemical processes in the cell, thus changing both biochemical parameters and enzyme activities of serum. Data on the effects of electric and magnetic fields on human health and other animals are inconsistent probably due to differences in the exposure conditions, populations and parameters studied $d^{[7-9]}$.

In the last decades, utilization of electricity has increased and diffused in both households and industries. The frequency of the current used in these systems is $0-300 \mathrm{~Hz}$. This frequency interval is termed Extremely Low Frequency Magnetic Field (ELF-MF), which is a non-ionizing radiation having photon energy too weak to break the atomic bonds. One of the most important fields of research in this topic is the investigation of the possible biological effects of power-line frequency $(50 / 60 \mathrm{~Hz}) \mathrm{MF}$. At these frequencies, male and female reproductive functions have been proposed as possibly sensitive targets for the biological actions of MF. However, experimental data on male reproduction are quite limited and contradictory $^{[10,11]}$.

The main goal of this study was to evaluate the possible direct effect of whole-body 5 and $50 \mathrm{~Hz}$ MF exposure on levels of glucose and cortisol hormone.

\section{MATERIALS AND METHODS}

Male Guinea pigs weighing $363.17 \pm 10.58 \mathrm{~g}$ average (8-9 weeks old) were kept in a room with a $12: 12$ light/dark photoperiod, temperature of $20-23^{\circ} \mathrm{C}$ and relative humidity of $50-60 \%$. In each experiment, 10-13 sham-exposed and another 10-13 exposed mice were kept in plastic cages and allowed free access to standard laboratory pellets (Altromin) and tap water. The MF exposure was carried out in four repeated experiments.

Magnetic field exposure: All procedures does base on Kula, 1985. The sinusoidal, 5 and $50 \mathrm{~Hz}$ MF was generated by a pair of double-wound coils connected to an internally developed, stabilized AC-current generator. The coils were embedded in molded epoxy resin to avoid vibration. The inner diameter of the coils was $42 \mathrm{~cm}$. The distance between the two parallel coils, mounted horizontally above and below the mouse cage, was 32 $\mathrm{cm}$. The orientation of MF was vertical. The magnetic flux density was measured with a Hall detector-type MF sensor and monitor (Lakeshore M420). 
Cortisol radioimmunoassay: Quantification of cortisol level was performed by RIA. In addition, blood samples were taken from exposured and control animals to check the levels of blood sera cortisol. cortisol (3.74 $\mathrm{TBq} / \mathrm{mmol}$ ) was obtained from Pasteur Institute, Tehran, Iran. The cortisol standard and antiserum were kindly donated by Dr. Shokrzadeh (Sari Medical School, Department of Pharmacy). The inter-and intraassay coefficient of variations was 9.4 and $6.5 \%$, respectively. Cross-reactivity was $7.9 \%$.

Glucose determination: Blood was taken from tail portion, collected in plastic Eppendorf tubes containing K3EDTA. At sacrifice, free-flowing blood was collected in plastic Eppendorf tubes. After centrifugation, serum was removed and the samples were then analyzed for levels of glucose serum by an auto analyzer instrument (AL Instruments, France). The data were analyzed by t-test and ANOVA using SPSS (version.12) computer software. A value of $\mathrm{p}<0.05$ and $<0.001$ was considered to be significant.

\section{RESULTS}

The mean values $( \pm$ SEM) of chortisol and Glucose levels for exposed and sham-exposed in Guinea Pigs are shown in Table 1 and 2. Statistical analysis gives evidence of significant difference between exposed and control groups.

There was no significant difference between 2 and $4 \mathrm{~h}$ exposured animals in I and II groups and was significant in group II $(50 \mathrm{~Hz}-0.207 \mu \mathrm{T}$ exposured $)$ both cortisol and Glucose levels in compared to the sham-exposed controls.

In the group subjected to $5 \mathrm{~Hz}-0.013 \mu \mathrm{T}$ exposures, no significant elevation in cortisol and Glucose levels was seen after a 2 or $4 \mathrm{~h}$, while the group subjected to $50 \mathrm{~Hz}-0.207 \mu \mathrm{T}$ exposure seen. The highest decrease in Glucose level seen $(79.16 \pm 15.39)$ and Cortisol (327.65 \pm 34.29$)$ after $2 \mathrm{~h}$ exposured to $50 \mathrm{~Hz}-0.207$ $\mu \mathrm{T}$. In group II, there was a statistically significant decrease in total serum Glucose and Cortisol content (Table 1 and 2). All of the groups showed changes in Glucose and Cortisol levels.

Table 1: Concentrations of cortisol (in $\mathrm{mg} \mathrm{dL}^{-1}$ ) in serum exposed to magnetic field in guinea pigs

\begin{tabular}{lll}
\hline $4 \mathrm{~h}$ & $2 \mathrm{~h}$ & Group \\
\hline $439.12 \pm 58.50$ & $568.46 \pm 25.4$ & $\mathrm{I}=5 \mathrm{~Hz}-0.013 \mu \mathrm{T}$ \\
$412.50 \pm 42.74^{\mathrm{b}}$ & $327.65 \pm 34.29^{\mathrm{a}}$ & II $=50 \mathrm{~Hz}-0.207 \mu \mathrm{T}$ \\
$532.25 \pm 54.67$ & $586.67 \pm 50.35$ & Control \\
\hline${ }^{\mathrm{a}}: \mathrm{p}<0.05$, $^{\mathrm{b}}: \mathrm{p}<0.001$, All data shown as mean \pm SEM
\end{tabular}

Table 2: Concentrations of glucose (in $\mathrm{mg} \mathrm{dL}^{-1}$ ) in serum exposed to magnetic field in guinea pigs

\begin{tabular}{lll}
\hline $4 \mathrm{~h}$ & $2 \mathrm{~h}$ & Group \\
\hline $114.33 \pm 4.99$ & $111.83 \pm 13.52$ & $\mathrm{I}=5 \mathrm{~Hz}-0.013 \mu \mathrm{T}$ \\
$77.66 \pm 9.32^{\mathrm{b}}$ & $79.16 \pm 15.39^{\mathrm{b}}$ & II $=50 \mathrm{~Hz}-0.207 \mu \mathrm{T}$ \\
$124.16 \pm 8.05$ & $113.66 \pm 8.13$ & Control \\
${ }^{\mathrm{b}}: \mathrm{p}<0.001$, All data shown as mean \pm SEM &
\end{tabular}

\section{DISCUSSION}

Many previous studies of the effect of electromagnetic fields on living organisms showed that the initial effect of an electromagnetic field is the triggering of key biochemical processes in various metabolic pathways ${ }^{[12-15]}$.

The effect of an electromagnetic field on the living organism is a complex phenomenon. The initial mechanism is physicochemical in nature and after wards biological effects develop. The physicochemical action of an electromagnetic field consists in electron, ion and dipolar, macro structural and electrolytic polarization. Other factors may also play a role, such as molecular excitation, biochemical activation, generation of radicals, chemical bond weakening, hydration change, altered relaxation time of atom vibration and altered spin of dipoles ${ }^{[14,15]}$. These physicochemical changes may affect the biochemical parameters of serum.many studies showed changes in protein levels the changes occurred in all electrophoretic in vivo protein fractions of serum; but the levels of albumins and y-globulins were most affected ${ }^{[16,17]}$.

In this study, we observed a decrease in Cortisol and Glucose levels. The decreases may have resulted from hormone synthesis in the Kidney, which is controlled by peptides hormones. The availability of tissue proteins, release of amino acids and their metabolism in the liver are triggered by the katabolic action of glucocorticoids but the changes observed in Glucose level can be attributed to accelerated glycolysis and glycogenolysis with a metabolic block of conversion of pyruvic acid to acetylocoenzyme A only. The action of glucocorticoids is also determined by the function of the liver and nutritional status ${ }^{[14,16,18]}$.

The results of our experiments show that wholebody MF exposure is able to decrease the Cortisol and Glucose level after $50 \quad \mathrm{~Hz}-0.207 \mu \mathrm{T}$. Further investigations are required to clarify the subcellular action of applied MF, as well as to establish the biological significance of this phenomenon.

\section{ACKNOWLEDGMENT}

Thanks are due to Colleagues in Faculty of Sciences (Urmia University) for their excellent technical assistance.

\section{REFERENCES}

1. Kato, M., K. Honma, T.Shigemitsu and Y. Shiga, 1994. Circularly polarized, sinusoidal, $50 \mathrm{~Hz}$ magnetic field exposure does not influence plasma testosterone levels of rats. Bioelectromagnetics, 15: 513-518.

2. Margonato, V., P. Nicolini, R. Conti, L. Zecca, A. Veicsteinas and P. Cerretelli, 1995. Biologic effects of prolonged exposure to ELF electromagnetic fields in rats. II. $50 \mathrm{~Hz}$ magnetic fields. Bioelectromagnetics, 16: 343-355. 
3. Zecca, L., C. Mantegazza, V. Margonato, P. Cerretelli, M. Caniatti, F. Piva, D. Dondi and N. Hagino, 1998. Biological effects of prolonged exposure to ELF electromagnetic fields in rats. III. $50 \mathrm{~Hz}$ electromagnetic fields. Bioelectromagnetics, 19: 57-66.

4. Picazo, M.L., M.P. Demiguel, V. Leyton, P. Franco, L. Varela, R. Paniagua and J.L. Bardasano, 1995. Long-term effects of ELF magnetic-fields on the mouse testis and serum testosterone levels. ElectroMagnetobiology, 14: 127-134.

5. Sert, C., M.Z. Akdag, M. Bashan, H. Buyukbayram and S. Dasdag, 2002. ELF magnetic field effects on fatty-acid composition of phospholipid fraction and reproduction of rat's testes. Electromagn. Biol. Med., 21: 19-29.

6. Al-Akhras, M.A., A. Elbetieha, M.K. Hasan, L. Al-Omari, H. Darmani and B. Albiss, 2001. Effects of extremely low frequency magnetic field on fertility of adult male and female rats. Bioelectromagnetics, 22: 340-344.

7. Elbetieha, A., M.A. Al-Akhras and H. Darmani, 2002. Long-term exposure of male and female mice to $50 \mathrm{~Hz}$ magnetic field: Effects on fertility. Bioelectromagnetics, 23: 168-172.

8. Heredia-Rojas, J.A., D.E. Caballero-Hernandez, F. Rodriguez, G. Ramos-Alfano and L.E. Rodriguez-Flores, 2004. Lack of alterations on meiotic chromosomes and morphological characteristics of male germ cells in mice exposed to a $60 \mathrm{~Hz}$ and $2.0 \mathrm{mT}$ magnetic field. Bioelectromagnetics, 25: 63-68.

9. Lee, J.S., S.S. Ahn, K.C. Jung, Y.W. Kirn and S.K. Lee, 2004. Effects of $60 \mathrm{~Hz}$ electromagnetic field exposure on testicular germ cell apoptosis in mice. Asian. J. Androl., 6:29-34.

10. De Vita, R., D. Cavallo, L. Raganella, P. Eleuteri, M.G. Grollino and A. Calugi, 1995. Effects of 50 $\mathrm{Hz}$ magnetic fields on mouse spermatogenesis monitored by flow cytometric analysis. Bioelectromagnetics, 16: 330-334.

11. Forgacs, Z., G. Thuroczy, K. Paksy and D.L. Szabo, 1998. Effect of sinusoidal $50 \mathrm{~Hz}$ magnetic field on the testosterone production of mouse primary Leydig cell culture. Bioelectromagnetics, 19: 429-431.
12. Kubinyi, Gy., G. Thuroczy, H. Sinay and D.L. Szabo, 1998. Magnetic field and the initial phase of the protein sythesis in newborn and adult mice. Electro-Magnetobiology, 17: 161-169.

13. Stoklosowa, S., 1982. Tissue culture of gonadal cells. Acta Biol. Acad. Sci. Hung., 33: 367-379.

14. Forgacs, Z., K. Paksy, P. Lazar and E. Tatrai, 1998. Effect of $\mathrm{Ni}^{2+}$ on the testosterone production of mouse primary Leydig cell culture. J. Toxicol. Environ. Health, 55: 213-224.

15. Joshi, N.J., S.B. Moodbidri and T.D. Nandedkar, 1987. Inhibition of A5-3p hydroxysteroid dehydrogenase activity in pre-implantation mouse embryos and their implantation by sheep ovarian follicular fluid peptide. Acta Endocrinol., 115: 183-188.

16. Kula, B., 1985. The effects of electric field-power frequency-on selected biochemical parameters in guinea pigs liver. Medycyna Pracy, 36: 356-362.

17. Phelps, P.V. and J.W. Laskey, 1989. Comparison of age-related changes in in vivo and in vitro measures of testicular steroidogenesis after acute cadmium exposure in the Sprague-Dawley rat. J. Toxicol. Environ. Health, 27:95-105.

18. Bordiushkov, N., I.A. Goroshinskaia, E.M. Frantsiiants, G.N. Tkacheva, E.I. Gorlo and I.V. Neskubina, 2000. Structural-functional changes in lymphocyte and erythrocyte membranes after exposure to alternating magnetic field. Voprosy Med. Khim., 46: 72-80. 